\title{
Origins of the Canadian Association for the Study of the Liver: A personal memoir
}

\author{
Jerome B Simon MD FRCPC FACG FACP
}

\begin{abstract}
JB Simon. Origins of the Canadian Association for the Study of the Liver: A personal memoir. Can J Gastroenterol 2012;26(9): 583-586.

The Canadian Association for the Study of the Liver (CASL) (Association Canadienne Pour L'Étude Du Foie) is a thriving organization. Although it was established more than a quarter of a century ago and has been successful since the beginning, most members are unaware of how CASL came into being or of its humble origins as a precursor club in the 1970s. The present article reviews those early days. It is written as a memoir because of the author's personal involvement and is based on detailed records, correspondence and handwritten notes from that era.
\end{abstract}

\author{
Les origines de l'Association canadienne pour \\ l'étude du foie : un mémoire personnel
}

L'Association canadienne pour l'étude du foie (ACÉF, Canadian Association for the Study of the Liver) est un organisme prospère et respecté. Même si elle a été fondée il y a plus d'un quart de siècle et qu'elle connaît le succès depuis sa création, la plupart des gens ne connaissent pas la genèse de l'ACÉF depuis ses humbles origines de club précurseur dans les années 1970. Le présent article s'attarde sur cette genèse. Il est rédigé sous forme de mémoire en raison de l'investissement personnel de l'auteur et fait appel aux dossiers détaillés, à la correspondance et aux notes manuscrites de l'époque. Un plus court résumé des origines de l'ACÉF a été publié il y a une vingtaine d'années.

Key Words: Canadian Liver Club; CASL

$\mathrm{T}$ he Canadian Association for the Study of the Liver (CASL) (Association Canadienne Pour L'Étude Du Foie) is a thriving organization. It was established more than 25 years ago and has been successful since the beginning; however, most members are unaware of how CASL came into being or of its humble origins as a precursor club in the 1970s. This article reviews those early days. It is written as a memoir because of my personal involvement but is based on detailed records, correspondence and handwritten notes from that era. A shorter summary of CASL's origins was published approximately two decades ago (1).

In the 1960s, hepatology was generally viewed as an important but relatively minor component of gastroenterology, and very few centres around the world were devoted to specialized training in liver diseases. The primary forum for the exchange of scientific information was the American Association for the Study of Liver Diseases (AASLD), which was founded in 1950 and met annually in Chicago (Illinois, USA) at the beginning of November. By the mid 1970s, a growing number of Canadian physicians and investigators had a special interest and expertise in the liver. Nearly all were members of the Canadian Association of Gastroenterology (CAG), which originated in the early 1960s and met each year in the dead of winter with the combined subspecialty societies of the Royal College of Physicians and Surgeons of Canada and the Canadian Society for Clinical Investigation (CSCI). Several of the physicians were also members of the AASLD and regularly attended the Chicago meetings, but there was no comparable Canadian organization to foster their interests.

\section{THE CANADIAN LIVER CLUB}

Credit for triggering a home-grown scientific society devoted to the liver belongs to Murray 'Woody' Fisher and the late Carl Goresky in 1977. At the time, Woody was a dynamic young specialist in Toronto (Ontario), trained in Pittsburgh (Pennsylvania, USA) and in England by Sheila Sherlock, while Carl was an established Montreal (Quebec) investigator whose reputation hinged on brilliant and esoteric studies of hepatic clearance. In January 1977 I received a letter signed by Woody and Carl which began "This letter is bound to offend a wide spectrum of individuals...", in which they argued that our country now had a sufficient critical mass of investigators to form a Canadian equivalent of the AASLD. The letter was sent to Canadian members of the AASLD and others known to have an interest in the liver, and it issued an open invitation to discuss this concept at an informal meeting during the Royal College/CSCI gathering later that month.

The meeting was held at the Sheraton Centre in Toronto on January 27, 1977, and was attended by 30 individuals. Although there was some unease about another gastroenterology-related organization, especially regarding potential weakening of the CAG and CSCI, the atmosphere was favourable and even enthusiastic. A five-member Steering Committee was therefore established to plan the new organization. In addition to Carl and Woody, the Steering Committee comprised Denis Marleau, one of the superb group of clinical researchers at the Hôpital St Luc in Montreal; Laurie Blendis, a clinicianinvestigator recently recruited to the University of Toronto (Toronto, Ontario) after an exceptional early career in England, under mentors such as Sir Christopher Booth, Roger Williams and Sir Francis Avery Jones; and myself. I was a junior faculty member at Queen's University in Kingston (Ontario), having trained in gastroenterology in Montreal followed by three years as a National Institutes of Health Fellow in the Liver Study Unit at Yale University (Connecticut, USA) under Gerald Klatskin.

The five of us met in Toronto on May 25, 1977 for a working lunch at Fenton's, one of the city's top restaurants. Stimulated by a delicious meal, we hammered out the major principles of the new organization. First, it would be an informal group called the Canadian Liver Club, without a constitution. This decision was taken deliberately to avoid any conflict with existing societies. Second, the Club would be apolitical and devoted primarily to the intellectual and social interests of its members, but would also work to strengthen existing institutions such as the CAG and CSCI. Third, membership would be open to any interested individuals. This point was initially contentious, with some of the Steering Committee favouring a requirement such as membership in the AASLD, but I argued for open membership and my position prevailed. Fourth, the Club would meet annually in association

Division of Gastroenterology, Queen's University, Kingston, Ontario

Correspondence and reprints: Dr Jerome B Simon, Division of Gastroenterology, Hotel Dieu Hospital, 166 Brock Street, Kingston, Ontario K7L 5G2.

Telephone 613-544-3400 ext 2491, fax 613-544-3114, e-mail simonj@queensu.ca

Received for publication January 12, 2012. Accepted January 16, 2012 


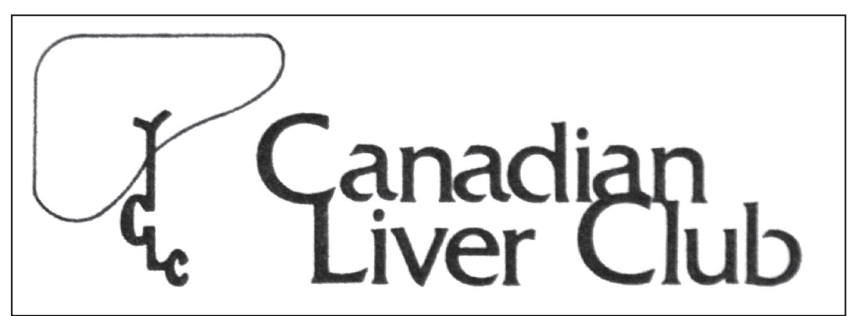

Figure 1) Logo of the Canadian Liver Club, based on a design by Woody Fisher in June 1977. The colour was dark red

with the Chicago AASLD meeting, with an informal format of dinner, a few scientific papers and an expert presentation. This point was, once again, to obviate any appearance of conflict with other Canadian organizations. Fifth, in keeping with its informal nature, the Club would be run by a six-person Steering Committee with regular turnover and rotating individual responsibilities; there would be no president or other fixed executive positions. Finally, the Club would accept administrative assistance from the Canadian Foundation for Diseases of the Liver (discussed below) but would not otherwise be associated with the Foundation.

A logo for the Club was designed by Woody (Figure 1) and an annual membership fee of $\$ 10$ was established. Rudy Danzinger, a surgeon at the University of Manitoba (Winnipeg, Manitoba), was invited to be the initial sixth member of the Steering Committee; he had been a Fellow at the Mayo Clinic (Rochester, Minnesota, USA) and was first author on the famous article reporting dissolution of gallstones by chenodeoxycholic acid. The Committee made plans for an inaugural meeting of the Canadian Liver Club that fall, which was held at the Hyatt Regency Hotel in Chicago on the evening of October 31, 1977 in conjunction with the AASLD meeting. Despite the Halloween timing, the meeting was a resounding success, with some 30 attendees enjoying a convivial dinner of crab bisque, roast beef and Grand Marnier soufflé washed down by a Beaujolais Supérieur, all for a cash price of $\$ 23.50$ (those were the days!). Scientific presentations were given by Denis Marleau, Vic Feinman, Jean-Gil Joly and Al Medline, and Carl Goresky presented a review talk titled 'Hepatic Uptake'.

Given the success of the inaugural meeting and favourable word of mouth, membership began to swell. By March 1978, the Canadian Liver Club had 63 members and a bank account of $\$ 362$ profit to play with. The membership stretched from Vancouver, British Columbia, to St John's, Newfoundland, and comprised a healthy smattering of surgeons, pathologists and basic scientists among the clinician majority. Steering Committee members were assigned various tasks by consensus (Figure 2). Laurie Blendis agreed to organize the scientific component of the next meeting, and I took on the technical arrangements. This proved to be more complex than I had envisioned, and involved back-and-forth negotiations with the secretary-treasurer of the AASLD, the Hyatt Regency Hotel and the AASLD's management company. In the end, however, it worked out well and the Club had a successful second meeting on November 6, 1978. The scientific program was well received, the meal was excellent, and the atmosphere was again friendly and informal. From that point onward, the Club continued to thrive with a similar format. The original Steering Committee was replaced in rotation by new blood, including among others Eldon Shaffer, Noel Williams, Cam Ghent, Bob Bailey, Jenny Heathcote and Lloyd Sutherland. Because several members complained about the evening timing of the get-togethers, in 1982 the meetings were switched to an early afternoon format, albeit with loss of a certain joie de viure that the dinner libations had previously fostered. The locale was also moved to the Chicago Marriott Hotel, which now housed the expanding attendance at the AASLD meetings.

As mentioned above, from its inception, the Club took pains to avoid conflicts with other Canadian societies, especially the CAG. At the same time, however, we wanted to tactfully enhance 'liver' input

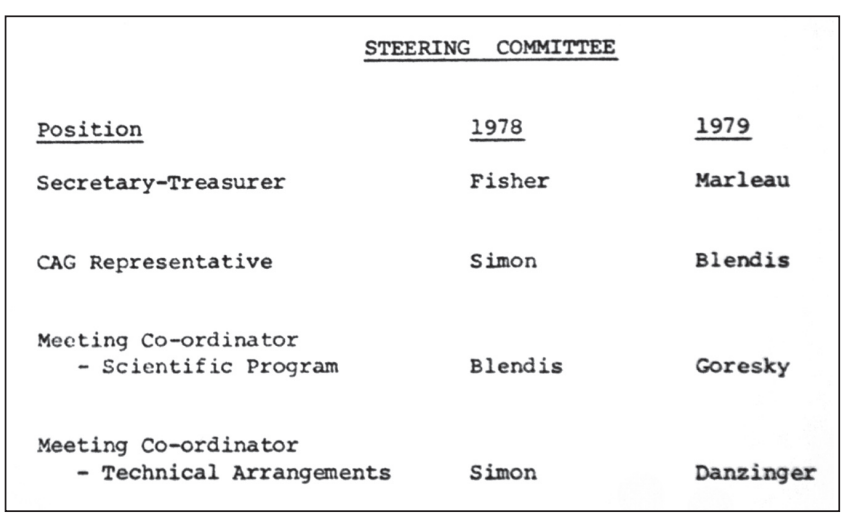

Figure 2) Initial members of the Canadian Liver Club's Steering Committee and their responsibilities, from the original Club records

into the selection of CAG councillors and scientific presentations. After our successful inaugural meeting, I agreed to act as initial liaison with the CAG because its president at the time was Fred Weinstein, an old friend who I had known since undergraduate days. I had an amicable discussion with Fred at the annual Royal College/CSCI meeting in January 1978, then wrote him a formal letter to assure the CAG that the Canadian Liver Club was not a splinter group of the $\mathrm{CAG}$ and that both organizations could actually be strengthened by greater hepatic input into CAG activities. This bore fruit, and Laurie Blendis then assumed CAG liaison with admirable success in securing a comfortable relationship with the more senior organization.

\section{TRANSFORMATION INTO CASL}

By 1984, most members of the Canadian Liver Club were convinced that the time was ripe for a more formal society, especially because hepatology was coming into its own as a specialty and liver transplantation was no longer an experimental procedure. The initiative was taken by Lloyd Sutherland at the University of Calgary (Calgary, Alberta), who had expertise in epidemiology and was on the Club's Steering Committee at the time. In September 1984, Lloyd sent a letter to Club members announcing that the upcoming annual meeting would be devoted to a discussion about the Club's future - specifically, whether it should be transformed into a Canadian Association for the Study of Liver Diseases, be incorporated into the CAG as a separate section or continue as the Canadian Liver Club but hold its meetings in Canada.

At the Club's Chicago meeting on November 9, 1984, Lloyd presented a detailed handwritten proposal for a Canadian Association for the Study of the Liver (Figure 3). This was heartily embraced by the attending members. As was the case seven years earlier, a Steering Committee was struck to act as a midwife for the nascent CASL. In addition to Lloyd, who chaired the Committee, members included Denis Marleau and Laurie Blendis again; Noel Williams, a hepatologist at Dalhousie University (Halifax, Nova Scotia) who became founding co-editor of the Canadian Journal of Gastroenterology; Eldon Shaffer, who trained in bile physiology with Donald Small in Boston (Massachusetts, USA) and was now head of the young Division of Gastroenterology at the University of Calgary; and Wayne Lautt, a pharmacologist and physiologist at the University of Manitoba with expertise in the hepatic circulation.

By mid 1985, the Committee had drawn up a constitution and series of bylaws for the organization, along with proposals for an Executive, Governing Board and Committees. An inaugural meeting of CASL was therefore announced for the fall. This historic meeting took place on November 4, 1985 at the Chicago Marriott Hotel, and was to be the last gathering held outside of Canada. The proposed constitution, bylaws and structure of the organization were ratified with minor changes, and a slate of executive officers, governors, and committee chairs was elected (Figure 4). Thus was born the Canadian Association for the Study of the Liver, with Eldon Shaffer as its first president. 


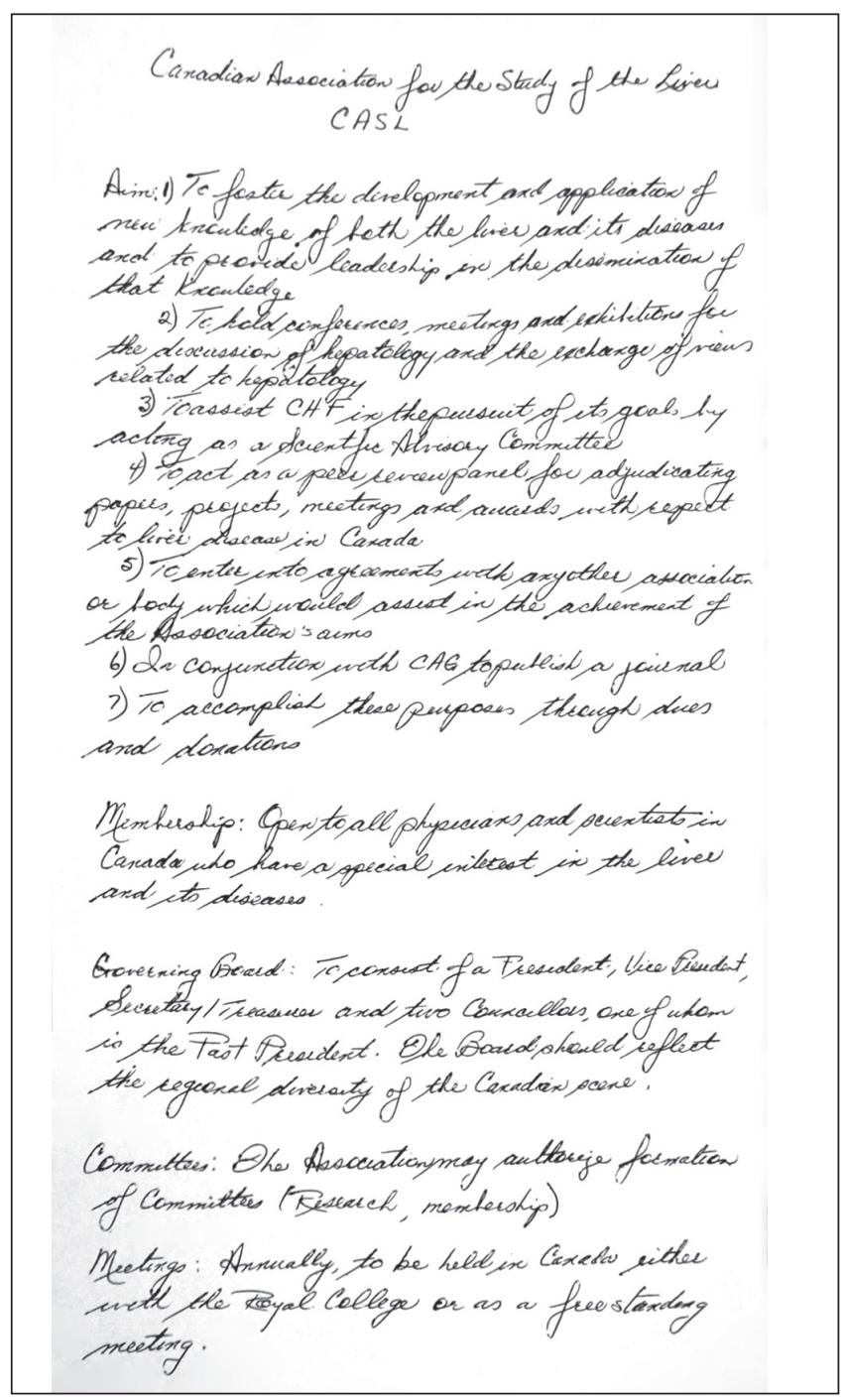

Figure 3) The original proposal for a Canadian Association for the Study of the Liver (CASL), presented by Lloyd Sutherland to the Canadian Liver Club on November 9, 1984

During the next few months, the committee chairs developed terms of reference for their committees, while the executive devoted energy to raising funds, attracting members and establishing relationships with other organizations. An annual membership fee of $\$ 40$ was established. As was hoped, the formal nature of CASL began to beneficially impact on its visibility in Canada and abroad. The CAG and CSCI both recognized CASL as a new national society and supported its activities, including by donations. Limited additional funding came from industry. Importantly, CSCI added a hepatology check box to its abstract form for the next Royal College/CSCI meeting and granted CASL a half day for abstract presentations. The CAG also agreed to expand the time it allotted to 'liver' papers at its portion of the meeting. Positive relations with the AASLD were established, and overtures to the International Association for the Study of the Liver (IASL) were initiated. These successes were a tribute to the talent and hard work of the new executive and to Laurie Blendis's skill as chair of the liaison committee.

These advances led to a very successful 1986 CASL meeting, which was held in Toronto as part of the annual Royal College/CSCI gathering. These combined conferences had shifted from January to September, mainly for weather reasons, and were still the primary scientific forum for virtually all of the Canadian subspecialty societies; the CAG had not yet hived itself off to hold its annual meeting independently. Jenny Heathcote ably served as CASL's representative

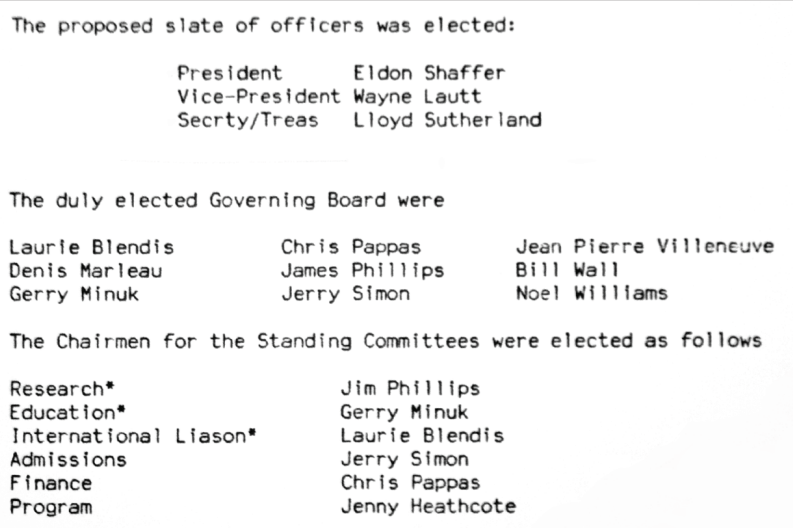

Figure 4) The founding Executive, Governors, and Committee chairs of the Canadian Association for the Study of the Liver (CASL), excerpted from the minutes of CASL's inaugural meeting held on November 4, 1985

for the local arrangements. High-quality abstracts were presented at two open sessions chaired by CASL members, and there were sufficient additional liver-related abstracts to fill a poster session as well. In addition, CASL achieved visibility through a well-attended symposium on treatable forms of liver disease sponsored by the Canadian Liver Foundation, during which Jenny presented the Foundation's Gold Medal to her former mentor, Dame Sheila Sherlock (the Foundation is discussed further below). At the CASL business meeting on September 23, chaired by Eldon Shaffer, reports were received from the various committees and approval was given to extend the terms of the founding officers for another year, after which an annual turnover would take place (this was later changed to two-year terms). Lloyd Sutherland presented a Treasurer's report documenting a paid membership of 65 individuals and a net $\$ 1,823$ cash on hand after expenses.

CASL continued to thrive thereafter and has never looked back. Its profile at the annual Royal College/CSCI meetings rapidly bloomed, largely due to the talents of Gerry Minuk, a hepatologist at the University of Manitoba who chaired CASL's Education Committee. I happened to fortuitously be on the Council of CSCI in the late 1980s, which also helped foster CASL input into the scientific programs. By serendipity, the fledgling organization received a major boost when the IASL unexpectedly decided to hold its 1988 conference in Canada, with CASL serving as host for this prestigious worldwide convention. The conference was originally intended for Cairo, Egypt, but political and logistic difficulties led Lawrie Powell, the Australian president of the IASL, to abandon Egypt in favour of Canada. This initially ruffled some feathers in the AASLD, but Eldon Shaffer and Laurie Blendis had earlier discussed a Canadian bid with the AASLD, and their tactful negotiations smoothed American support for Canada as host. The IASL convention was held in Toronto in early November 1988 and was highly successful. I was president of CASL at the time but I had little to do except share the dais at the opening session and look proud - all the work had been done by the local organizing committee, chaired by Laurie Blendis with the assistance of several other outstanding CASL members including Gary Levy, Jenny Heathcote, Chris Pappas and Vic Feinman. The success and high quality of the conference brought CASL visibility and plaudits on the international stage, not to mention a substantial boost to its coffers.

Thereafter, the organization continued to grow in membership, scientific clout and financial stability, with only a few minor bumps along the way. Table 1 lists the presidents of CASL during its first decade, but equal kudos belongs to the numerous other talented and dedicated individuals who served CASL's interests with selfless devotion, and were responsible for the flourishing and respected organization it remains today. 
TABLE 1

Presidents of the Canadian Association for the Study of the Liver during its first decade

\begin{tabular}{lll}
\hline Year & President & Affiliation \\
\hline 1985-1987 Eldon A Shaffer & University of Calgary, Calgary, Alberta \\
1987-1988 W Wayne Lautt & University of Manitoba, Winnipeg, Manitoba \\
1988-1989 Jerome B Simon & Queen's University, Kingston, Ontario \\
1989-1990 Lloyd Sutherland & University of Calgary \\
1990-1991 Laurence M Blendis & University of Toronto, Toronto, Ontario \\
1991-1992 Gerald Y Minuk & University of Manitoba \\
1992-1994 Pierre-Michel Huet & Université de Montréal, Montreal, Quebec \\
1994-1996 E Jenny Heathcote & University of Toronto \\
\hline
\end{tabular}

\section{RELATIONSHIPS WITH THE CANADIAN LIVER FOUNDATION}

In contrast to every other country with a lay foundation supporting hepatic interests, Canada's lay group uniquely antedated the nation's scientific society. In fact, the Canadian Liver Foundation in its initial manifestation was the world's first lay organization devoted to liver disease. It was born in October 1969 as the Medical Sciences Research Foundation, incorporated in the province of Ontario "to encourage and foster research into diseases of the liver and such other medical research as may be approved from time to time by the directors of the Corporation" (2). Its name was changed to the Canadian Hepatic Foundation in 1971, then a few years later to the Canadian Foundation for Diseases of the Liver and, ultimately, to the Canadian Liver Foundation. Announcement of the Canadian Hepatic Foundation's existence in 1971 came as a surprise because there had been no consultation with the Canadian community of medical professionals. Moreover, the Foundation's title was a misnomer because its initial activities were sharply focused in Toronto rather than nationwide. As a result of these murky beginnings, physicians and scientists across the country initially viewed the Foundation with a degree of skepticism.

This soon changed, however, when the Foundation wisely established a Medical Advisory Board headed by Andrew Sass-Kortsak, a senior pediatrician at The Hospital for Sick Children (Toronto, Ontario) who was a world-renowned expert on Wilson disease and a man of impeccable integrity. Andrew's stellar reputation led several professionals around the country to accept his invitation to join the Board, including Bernie Badley (Halifax), Laurie Dunn (Vancouver), Carl Goresky (Montreal), Bernie Langer (Toronto), Ron Wensel (Edmonton), André Viallet (Montreal), Woody Fisher (Toronto) and myself. The Foundation provided support for young investigators and trainees, along with educational resources for the public. It fell on hard financial times for a few years, but was rejuvenated in the mid 1980s under new leadership, which enabled it to establish several local chapters throughout the country and fund peer-reviewed training fellowships, operating grants to junior investigators, summer student awards, scientific symposia and an annual Gold Medal award. A 'think tank' retreat with the CASL executive in 1988 clarified and solidified the relationship between the two organizations, and gave CASL a greater role in determining the priorities, terms of reference and peer reviewing of the Foundation's programs. As a tribute to Andrew SassKortsak after his death in 1986, the Foundation established an annual award in his name beginning in 1990. In parallel with the growth and success of both organizations, the relationship and interaction between CASL and the Canadian Liver Foundation have remained beneficial and mutually supportive to this day.

ACKNOWLEDGEMENTS: The author thanks colleagues in CASL who encouraged him to write this article, especially Drs Winnie Wong and Eric Yoshida. He is also grateful for helpful comments provided by Drs Eldon Shaffer, Laurie Blendis, Gerry Minuk, Lloyd Sutherland, Woody Fisher, Eve Roberts and Sam Lee.

\section{REFERENCES}

1. Sutherland LR. The Canadian Association for the Study of the Liver. In: Morley TP, ed. Medical Specialty Societies of Canada. Toronto: Associated Medical Services, Inc. 1991:159-63.

2. Province of Ontario Letters Patent Incorporating the Medical Sciences Research Foundation, October 20, 1969. 


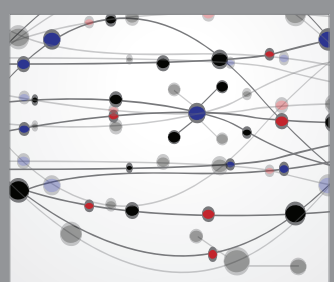

The Scientific World Journal
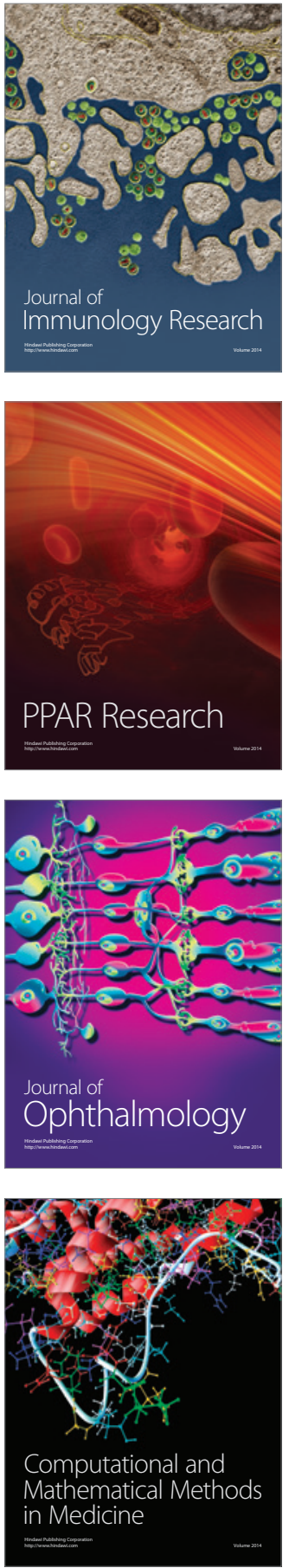

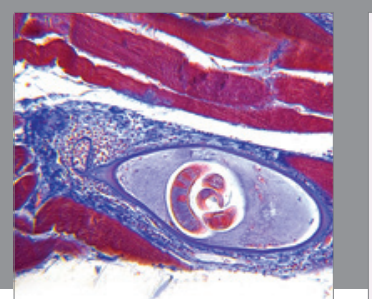

Gastroenterology Research and Practice

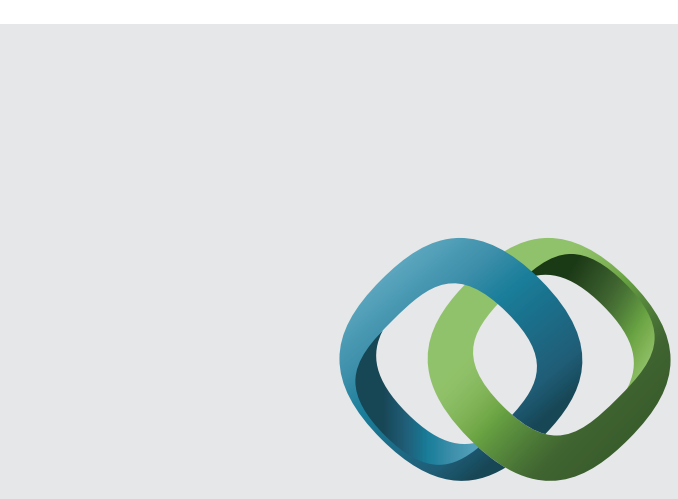

\section{Hindawi}

Submit your manuscripts at

http://www.hindawi.com
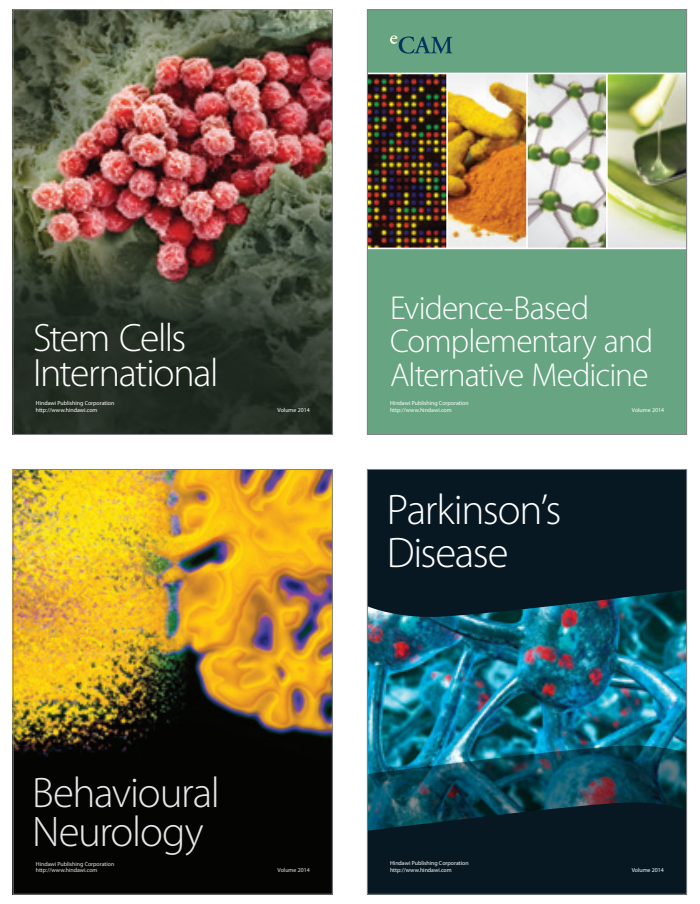
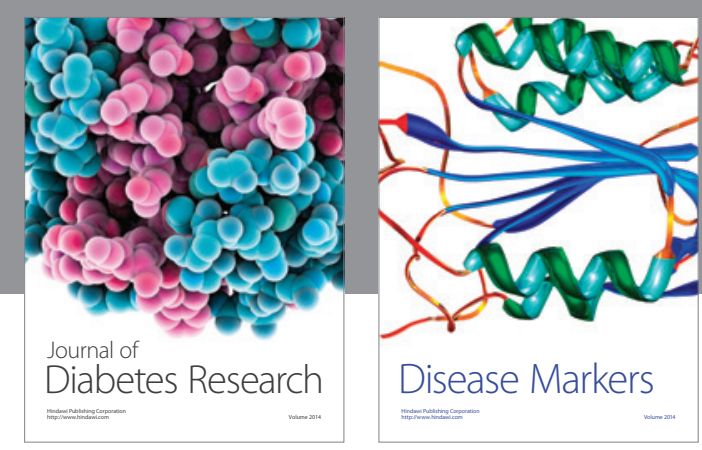

Disease Markers
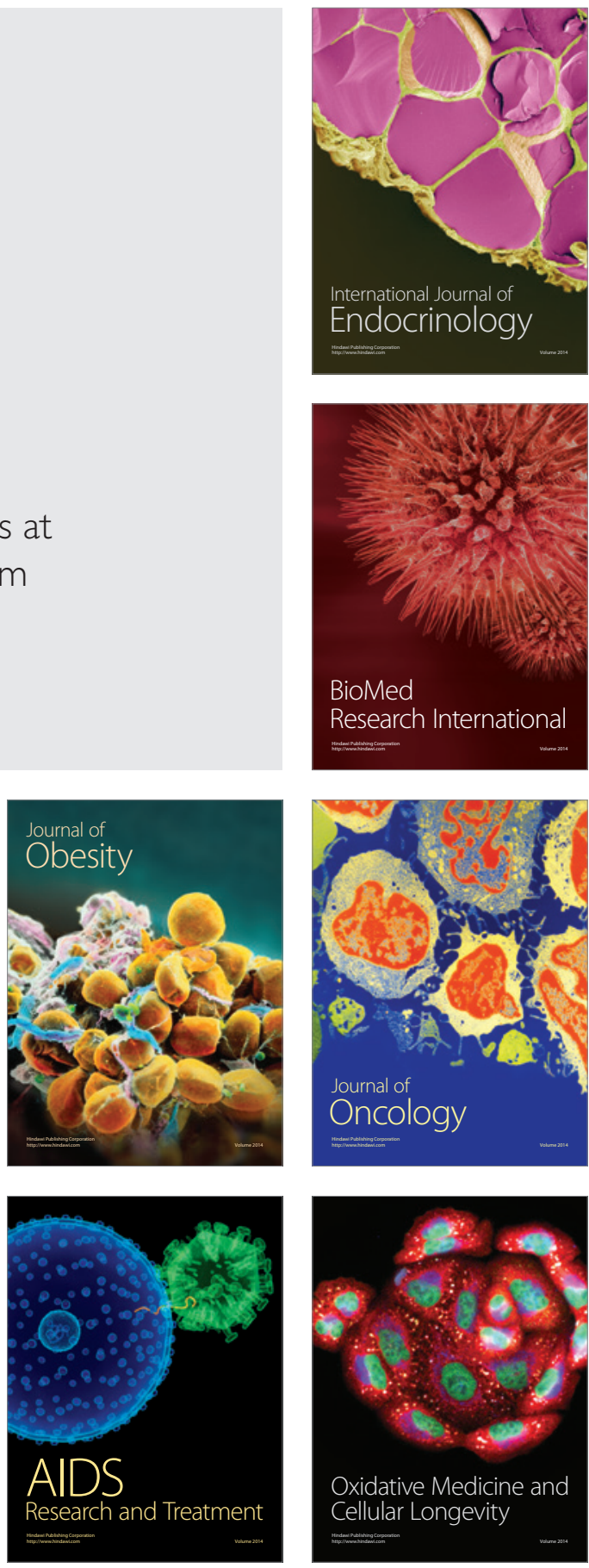